\section{Staging classification for cancer of the ovary and the fallopian tube should include in situ carcinoma}

To the editor: We read with interest the almost identical articles on staging classification for ovarian and fallopian tube cancer that were published in several journals [1-8]. What is missing in the staging classification is the in situ carcinoma or Tis for ovary and fallopian tube. Cancer staging is important and necessary for explaining epidemiologic changes, defining the disease at presentation, planning adequate treatment and evaluating the overall impact of new therapies [2].

In situ carcinoma of the ovary is extremely rare [9]. In situ carcinoma of the fallopian tube on the other hand is not so rare as one would expect. In situ carcinoma of the fallopian tube is found in $3 \%$ to $12 \%$ of the BRCA carriers who have a prophylactic removal of the tubes $[10,11]$. It is hypothesized that the fallopian tube is the origin of ovarian cancer. Clinical studies are ongoing to test this idea. An in situ carcinoma doesn't metastasize but it can give implant lesions in the abdomen or lead to involvement of the ascites or peritoneal washings.

Due to the raised awareness and the improved imaging more and more in situ cancers of the fallopian tube will be detected. Ovarian cancer and tubal cancer prevention strategy is mainly based on surgery. It is therefore important to stage these in situ carcinomas correctly in order to understand each other and to allow treatment comparising.

There are 4 possible staging classification for Tis: (1) Tis without implants or involvement of the ascites and peritoneal washings; (2) Tis with implants but without or involvement of the ascites and peritoneal washings; (3) Tis with implants and involvement of the ascites and peritoneal washings; (4) Tis without implants but with involvement of the ascites and peritoneal washings. Furthermore all women with an ovarian, fallopian tube or peritoneum cancer should have a genetic testing for BRCA mutation. This should also be recorded in the staging classification.

In the era of personalized cancer medicine accurate staging is essential, as it assigns patients to a specific group with specific treatments possibilities and consequently improved survival. Only if you look for things you will find it and you can improve it.

\section{CONFLICT OF INTEREST}

No potential conflict of interest relevant to this article was reported.

\section{REFERENCES}

1. Prat J; FIGO Committee on Gynecologic Oncology. Staging classification for cancer of the ovary, fallopian tube, and peritoneum. Int J Gynaecol Obstet 2014;124:1-5.

2. Mutch DG, Prat J. 2014 FIGO staging for ovarian, fallopian tube and peritoneal cancer. Gynecol Oncol 2014;133:401-4.

3. Prat J; FIGO Committee on Gynecologic Oncology. FIGO's staging classification for cancer of the ovary, fallopian tube, and peritoneum: abridged republication. J Gynecol Oncol 2015;26:87-9.

4. Prat J; FIGO Committee on Gynecologic Oncology. Abridged republication of FIGO's staging classification for cancer of the ovary, fallopian tube, and peritoneum. Eur J Obstet Gynecol Reprod Biol 2015;188:133-5.

5. Prat J, Belhadj H, Berek J, Bermudez A, Bhatla N, Cain J, et al. Abridged republication of FIGO's staging classification for cancer of the ovary, fallopian tube, and peritoneum. Eur J Gynaecol Oncol 2015;36:367-9.

6. Prat J; FIGO Committee on Gynecologic Oncology. Staging classification for cancer of the ovary, fallopian tube, and peritoneum: abridged republication of guidelines from the International Federation of Gynecology and Obstetrics (FIGO). Obstet Gynecol 2015;126:171-4.

7. Prat J; FIGO Committee on Gynecologic Oncology. Abridged republication of FIGO's staging classification for cancer of the ovary, fallopian tube, and peritoneum. Cancer 2015;121:3452-4.

8. Prat J. Ovarian, fallopian tube and peritoneal cancer staging: rationale and explanation of new FIGO staging 2013. Best Pract Res Clin Obstet Gynaecol 2015;29:858-69.

9. Inoue K, Tsubamoto H, Hao H, Tamura K, Hashimoto-Tamaoki T. Ovarian carcinoma in situ of presumable fallopian tube origin in a patient with Lynch syndrome: a case report. Gynecol Oncol Case Rep 2013;5:61-3.

10. Leeper K, Garcia R, Swisher E, Goff B, Greer B, Paley P. Pathologic 
findings in prophylactic oophorectomy specimens in high-risk women. Gynecol Oncol 2002;87:52-6.

11. Callahan MJ, Crum CP, Medeiros F, Kindelberger DW, Elvin JA, Garber $J$ E, et al. Primary fallopian tube malignancies in BRCA-positive women undergoing surgery for ovarian cancer risk reduction. J Clin Oncol 2007;25:3985-90.

\section{Wiebren A. A. Tjalma}

Gynecological Oncology Unit, Department of Obstetrics and Gynecology, Antwerp University Hospital, University of Antwerp, Edgem, Belgium

Correspondence to Wiebren A. A. Tjalma

Gynecological Oncology Unit, Department of Obstetrics and Gynecology, Antwerp University Hospital, University of Antwerp, Wilrijkstraat 10, 2650 Edegem, Belgium.E-mail:Wiebren.Tjalma@uza.be

http://dx.doi.org/10.3802/jgo.2015.26.4.355 